\title{
PRODUÇÃO, COMPOSIÇÃO BROMATOLÓGICA E ÍNDICE DE CLOROFILA DE BRAQUIÁRIAS APÓS O CONSÓRCIO COM MILHO\#
}

\author{
PRODUCTION, CHEMICAL COMPOSITION AND CHLOROPHYLL INDEX OF \\ BRACHIARIA SPP. AFTER THE INTERCROP WITH CORN
}

\author{
Pariz, C.M. ${ }^{1 *}$, Andreotti, M. ${ }^{2 A}$, Bergamaschine, A.F. ${ }^{3}$, Buzetti, S. ${ }^{2 B}$, Costa, N.R. ${ }^{2 C}$ \\ e Cavallini, M.C. ${ }^{2 D}$
}

${ }^{1}$ FMVZ/Unesp-Botucatu. São Paulo. Brasil. *cmpzoo@gmail.com

${ }^{2}$ Departamento de Fitossanidade. Engenharia Rural e Solos. FE/Unesp-Illha Solteira. São Paulo. Brasil. Adreotti@agr.feis.unesp.br; ${ }^{B}$ sbuzetti@agr.feis.unesp.br; ' nidiamagrela@hotmail.com; 'Dcecicavallini@gmail.com ${ }^{3}$ Departamento de Biologia e Zootecnia. FE/Unesp-Ilha Solteira.São Paulo. Brasil. berga@bio.feis.unesp.br

\section{PALAVRAS CHAVE ADICIONAIS}

Fibra em detergente neutro. Fibra em detergente ácido. Integração lavoura-pecuária. Nitrogênio. Nutrientes digestíveis totais. Proteína bruta.

\section{RESUMO}

Avaliou-se o efeito da adubação com 0, 50, 100 e $200 \mathrm{~kg} / \mathrm{ha}$ de $\mathrm{N}$ aplicadas em cada um dos 4 intervalos de crescimento no inverno/primavera sobre a produtividade de matéria seca em 30 dias (PMS), o índice de clorofila foliar (ICF) e os teores de nutrientes digestíveis totais (NDT), proteína bruta (PB), fibra em detergente neutro (FDN), fibra em detergente ácido (FDA) e lignina, bem como, as equações de correlação do ICF com a PMS e o teor de PB nos capins marandu e ruziziensis após o consórcio com milho em um Latossolo Vermelho Distroférrico sob irrigação. As maiores PMS ocorreram com o aumento do fotoperíodo, no entanto, houveram respostas diferenciadas deste atributo ao longo dos cortes, entre e dentre os capins quanto à adubação nitrogenada. Em sistema de integração lavoura-pecuária irrigado sob condições de cerrado é tecnicamente viável o estabelecimento dos capins marandu e ruziziensis pelo consórcio com o milho no momento da semeadura ou por ocasião da adubação nitrogenada de cobertura. Na ausência de adubação $N$ foi produzida quantidade satisfatória de forragem, com PMS média de $1733 \mathrm{~kg} / \mathrm{ha}$, na época de maior escassez de volumoso para os animais (inverno/primavera). No entanto, a

\footnotetext{
"Projeto financiado pela Capes (Bolsa de mestrado
} ao $1^{\circ}$ autor).

\section{AdDitionAL KEYWORDS}

Crop-livestock integration. Crude protein. Neutral detergent fiber. Acid detergen fiber. Nitrogen. Total digestible nutrients.

adubação N, após a colheita do milho elevou a PMS e melhorou a composição bromatológica dos capins, com aumento do ICF e dos teores de PB e NDT, e reduziu os teores de FDN e FDA no inverno/ primavera. As melhores equações de correlação em função do ICF foram logarítima para a PMS e potencial para a PB do capim-marandu e potencial para ambos os atributos do capim-ruziziensis.

\section{SUMMARY}

We evaluated the effect of fertilization with 0 , 50,100 and $200 \mathrm{~kg} / \mathrm{ha}$ of $\mathrm{N}$, applied in each four growth intervals in the winter/spring season on dry matter yield in 30 days (DMY), leaf chlorophyll index ( $\mathrm{LCl}$ ) and total digestible nutrients (TDN), crude protein (CP), neutral detergent fiber (NDF), acid detergent fiber (ADF) and lignin contents, and correlation equations of $\mathrm{LCl}$ with DMY and $\mathrm{CP}$ content in the marandu and ruziziensis grasses after intercrop arrangements with corn in Red Latosol (Oxisol) under irrigation. The major DMY occurred with photoperiod increasing, however, there were different responses to this attribute over of growth intervals, between and among the grasses with the $\mathrm{N}$ fertilization. In irrigated croplivestock integration under savannah soil is technicality viable the cultivation of marandu and ruziziensis grasses, established by intercrop with 
corn at sowing or at the $\mathrm{N}$ fertilization. As even, in the $\mathrm{N}$ fertilization absence, produced satisfactory amounts of forage, with $1733 \mathrm{~kg} / \mathrm{ha}$ (DMY), at the time of greatest scarcity of roughage to animals (winter/spring season). However, after the corn harvest, the $\mathrm{N}$ fertilization increase the DMY and improves the chemical composition, increasing the $\mathrm{LCl}$, and $\mathrm{CP}$ and TDN contents, and decreasing NDF and ADF contents in the winter/spring season. The best correlation equations in function of LCI were logatithmica for DMY and potential for $\mathrm{CP}$ of the marandu grass and potential for both attributes of the ruziziensis grass.

\section{INTRODUÇÃO}

A degradação das pastagens ao longo dos anos, principalmente em função de sua má formação e incorreto manejo, têm sido um dos grandes problemas para a atividade pecuária,afetando a sua sustentabilidade. Aproximadamente 80 milhões de ha de pastagens (aproximadamente $70 \%$ das pastagens cultivadas) do Brasil são ocupados pelo capim-marandu (Brachiaria brizantha cv. marandu), formando extensos monocultivos, especialmente na região de cerrado (Landers, 2007).

Têm-se buscado técnicas visando a diminuição dos custos, para a formação, recuperação e reforma de pastagens, sendo que a integração lavoura-pecuária (ILP) sob sistema plantio direto (SPD) em diversas regiões do mundo tem-se tornado opção vantajosa, beneficiando a produção de grãos e a pecuária, além de proporcionar resultados sócio-econômicos e ambientais positivos (Kluthcouski et al., 2000; Landers, 2007; Tracy e Zhang, 2008).

Entre as modalidades de ILP no Brasil, destaca-se o cultivo consorciado de espécies forrageiras tropicais com culturas graníferas, utilizando a forragem para atividade pecuária após a colheita da cultura granífera e, em seguida, formação de palhada para continuidade do SPD. Esse consórcio pode ser realizado simultaneamente ou por ocasião da adubação $\mathrm{N}$ de cobertura (10-20 dias após a emergência do milho) sem comprometimento na produtividade de grãos (Kluthcouski et al., 2000).

O índice de clorofila nas lâminas foliares (índice SPAD ou ICF) geralmente correlaciona-se com o teor de $\mathrm{N}$, viabilizando o diagnóstico prévio de uma possível deficiência (Rocha et al., 2005). Ainda são escassas as pesquisas correlacionando tais índices com a composição bromatológica e a produtividade das forrageiras perenes tropicais manejadas intensivamente em sistemas de ILP sob irrigação, em que a necessidade de adubação $\mathrm{N}$ na fase inicial é alta. Assim, objetivou-se avaliar a produtividade de matéria seca, o índice de clorofila foliar (ICF) e a composição de Brachiaria brizantha cv. marandu e de Brachiaria ruziziensis, adubadas com $\mathrm{N}$ e submetidas a diferentes intervalos de crescimento no inverno/primavera após o consórcio com milho, bem como, analisar a correlação destes atributos com o ICF.

\section{MATERIALE MÉTODOS}

O experimento foi conduzido de novembro de 2007 a outubro de 2008, na Fazenda de Ensino, Pesquisa e Extensão, pertencente à Faculdade de Engenharia (FE/Unesp), área de Produção Vegetal, localizada no município de Selvíria, Estado de Mato Grosso do Sul (2020' 50" S e 512 24'26" W). O tipo climático é Aw (classificação de Köppen), tropical úmido, com estação chuvosa no verão e seca no inverno (tabela I).

O solo da área é um Latossolo Vermelho Distroférrico, classificado conforme Embrapa (2006). Os atributos físicos e químicos anteriormente à instalação do experimento na camada de 0 a $0,20 \mathrm{~m}$ do solo apresentaram os seguintes valores: densidade do solo $=1,31 \mathrm{~kg} / \mathrm{dm}^{3}$; macro, micro e porosidade total $=0,147 ; 0,334$ e 0,4815 , respectivamente; $\mathrm{pH}\left(\mathrm{CaCl}_{2}\right)=5,1$; M.O. = $28 \mathrm{~g} / \mathrm{dm}^{3} ; \mathrm{H}+\mathrm{Al}=22,2 \mathrm{mmol}_{\mathrm{c}} / \mathrm{dm}^{3} ; \mathrm{P}$ (resina) $=18 \mathrm{mg} / \mathrm{dm}^{3} ; \mathrm{K}^{+}, \mathrm{Ca}^{2+} \mathrm{e} \mathrm{Mg}^{2+} \stackrel{\mathrm{c}}{=}$ 3,2; 19,0 e 11,0 mmol $/ \mathrm{dm}^{3}$, respectivamente, e $\mathrm{V}=59,9 \%$. 
A área experimental apresentava um histórico de cinco anos em SPD em fase inicial/ transição com as culturas de milho, soja, sorgo forrageiro, feijão guandu, Brachiaria brizantha e feijão, sendo a cultura anterior o consórcio de milho com os capins. A área foi irrigada por aspersão (pivô central), quando necessário, em função de déficits hídricos, durante todo o período experimental.

O delineamento experimental utilizado foi o de blocos casualizados, em parcelas subdivididas, com quatro repetições. As parcelas constituíram-se de quatro tratamentos (consórcio) dos capins com o milho na safra 2007/08: B. brizantha cv. marandu (capim-marandu) semeado simultaneamente (BS), B. Brizantha cv. marandu (capimmarandu) semeado por ocasião da adubação nitrogenada de cobertura (BC), B. ruziziensis (capim-ruziziensis) semeado simultaneamente (RS) e B. ruziziensis (capim-ruziziensis) semeado por ocasião da adubação nitrogenada de cobertura (RC), e nas subparcelas, a ausência de adubação nitrogenada e as doses de N (50, 100 e 200 $\mathrm{kg} /$ ha de $\mathrm{N}$ ), aplicadas no capim em cada um dos quatro intervalos de crescimento de 30 dias no inverno/primavera, sendo os cortes ao longo dos intervalos realizados na mesma subparcela. As parcelas apresentavam 90 $\mathrm{m}^{2}$ e as subparcelas $18 \mathrm{~m}^{2}$ de área útil. Foi semeado o híbrido simples de milho AG 8088 (ciclo precoce), com a finalidade de produção de grãos (espaçamento de $0,90 \mathrm{~m}$ nas entrelinhas). A adubação mineral de semeadura constou da aplicação de $20 \mathrm{~kg} /$ ha de $\mathrm{N}, 70 \mathrm{~kg} / \mathrm{ha}$ de $\mathrm{P}_{2} \mathrm{O}_{5}$ e $40 \mathrm{~kg} / \mathrm{h}$ a de $\mathrm{K}_{2} \mathrm{O}$ (250 kg do fertilizante formulado 08-28-16/ ha) e adubação mineral de cobertura constou da aplicação de $100 \mathrm{~kg} /$ ha de $\mathrm{N}$ (uréia).

Independente do consórcio, os capins foram semeados em espaçamento de $0,34 \mathrm{~m}$ na quantidade de $7 \mathrm{~kg} / \mathrm{h}$ a de sementes (VC= $76 \%$ ), sendo que nas parcelas em que os capins foram semeados simultaneamente ao milho (20/11/2007), realizou-se operação mecanizada com outra semeadora aduba- dora de discos para SPD, enquanto que nas parcelas em que os capins foram semeados na adubação nitrogenada de cobertura do milho (19/12/2007), as sementes foram misturadas ao adubo pouco antes da semeadura e acondicionadas no compartimento de fertilizante da semeadora adubadora. Em todos os consórcios, as sementes dos capins foram depositadas no solo na profundidade de $30 \mathrm{~cm}$. Em 17/12/ 2007 aplicou-se herbicida à base de Nicosulfuron (8 g do ingrediente ativo/ha), visando amenizar o crescimento dos capins semeados simultaneamente ao milho.

A colheita do milho ocorreu em 25/04/ 2008 e em 10/06/2008, as unidades experimentais foram uniformizadas com roçadora mecânica, adotando como referência 20 cm em relação à superfície do solo, com o intuito de estimular o perfilhamento e padronizar a idade fenológica dos capins entre os intervalos de crescimento, simulando um corte de homogeneização dos capins sem remoção

Tabela I. Dados climáticos durante a condução do experimento, 2007/2008. (Climatic data during the conduct of the experiment, 2007/2008 year).

\begin{tabular}{cccccc}
\hline \multicolumn{7}{c}{ temperatura ${ }^{\circ} \mathrm{C}$} \\
\multicolumn{7}{c}{ máx } & mín & méd & PP, mm & FP,h/d \\
\hline 2007 & & & & & \\
nov & 31,0 & 20,9 & 25,6 & 167,5 & 13,00 \\
dez & 32,6 & 21,7 & 26,5 & 199,7 & 13,20 \\
2008 & & & & & \\
jan & 31,0 & 21,1 & 25,5 & 434,8 & 13,10 \\
fev & 31,1 & 20,8 & 25,2 & 204,0 & 12,70 \\
mar & 30,4 & 20,0 & 24,8 & 293,4 & 12,10 \\
abr & 30,7 & 19,8 & 24,5 & 176,8 & 11,50 \\
mai & 27,0 & 15,4 & 20,8 & 62,2 & 11,10 \\
jun & 29,9 & 14,9 & 21,8 & 0,0 & 10,80 \\
jul & 30,2 & 14,7 & 21,9 & 0,0 & 10,90 \\
ago & 32,2 & 16,8 & 24,0 & 17,5 & 11,30 \\
set & 31,0 & 16,8 & 23,5 & 10,9 & 11,90 \\
out & 32,9 & 20,4 & 26,3 & 102,6 & 12,50 \\
\hline
\end{tabular}

PP: Precipitação; FP: Fotoperíodo (horas/dia). 
do material da área, permanecendo a palhada sobre a superfície do solo. Procedeu-se então, aplicações das doses de N (uréia) em cobertura, distribuídas nas entrelinhas dos capins, sendo a primeira adubação em 30/ $06 / 2008$. Os cortes foram realizados em 30/ 07/2008, 29/08/2008, 29/09/2008 e 29/10/ $2008\left(1^{\circ}, 2^{\circ}, 3^{\circ}\right.$ e $4^{\circ}$ intervalo de crescimento, respectivamente), sendo que as adubações foram realizadas logo após o corte dos capins com roçadora mecânica a uma altura de 30 cm em relação à superfície do solo com posterior retirada do material, em que principalmente as folhas foram exportadas da área. Antes da colheita mecânica, nesta mesma altura, para fim de amostragem, coletou-se $0,25 \mathrm{~m}^{2}$ da parcela com auxílio de um quadrado de metal, para determinação da produtividade de matéria seca em 30 dias (PMS) (estufa a $65^{\circ} \mathrm{C}$ até massa constante) e realizaram-se análises laboratoriais para determinação dos teores de proteína bruta (PB), fibra em detergente neutro (FDN), fibra em detergente ácido (FDA) e lignina, conforme metodologia contida em Silva e Queiroz (2002), e estimativa dos nutrientes digestíveis totais (NDT), conforme Cappelle et al. (2001).

A determinação do índice de clorofila foliar (ICF) foi efetuada no momento do corte dos capins, utilizando-se clorofilômetro digital (CFL 1030 - Falker) para leituras, na posição do terço médio da lâmina de folhas recém-expandidas (Abreu e Monteiro, 1999), realizando-se 20 leituras na subparcela, das quais descartaram-se as discrepantes, utilizando-se para a média apenas as cinco mais próximas. Os dados foram submetidos à análise de variância (teste $\mathrm{F}$ ) e as doses de $\mathrm{N}$ ajustadas por

Tabela II. Produtividade de matéria seca em 30 dias ( $\mathrm{kg} / \mathrm{ha}$ ) dos capins marandu e ruziziensis após o consórcio com milho, intervalos de crescimento $\left(1^{\circ}, 2^{\circ}, 3^{\circ}\right.$ e $\left.4^{\circ}\right)$ e doses de $N$. (Dry matter yield in 30 days of marandu (B) and ruziziensis (R) grasses after intercrop with corn, growth intervals $\left(1^{\circ}, 2^{\circ}, 3^{\circ}\right.$ and $\left.4^{\circ}\right)$ and nitrogen fertilization).

\begin{tabular}{|c|c|c|c|c|c|c|c|}
\hline & & & Dose c & $(\mathrm{kg} / \mathrm{ha}$ & & Equação estimada & $\mathrm{R}^{2}$ \\
\hline & & 0 & 50 & 100 & 200 & & \\
\hline $1^{\circ}$ & BS & 1150 & 1450 & 1550 & 2100 & $1160,00+4,60 \mathrm{~N}$ & $0,981^{* \star}$ \\
\hline & $B C$ & 1050 & 1250 & 1400 & 1750 & $1060,00+3,46 \mathrm{~N}$ & $0,998 * *$ \\
\hline & RS & 1200 & 1450 & 1550 & 1900 & $1230,00+3,37 \mathrm{~N}$ & $0,985^{\star \star}$ \\
\hline & $\mathrm{RC}$ & 1100 & 1250 & 1500 & 1800 & $1100,00+3,57 \mathrm{~N}$ & $0,990^{* \star}$ \\
\hline $2^{\circ}$ & BS & 1450 & 3550 & 3450 & 3800 & $1645,00+33,45 N-0,12 N^{2}$ & $0,868^{* *}$ \\
\hline & $\mathrm{BC}$ & 1450 & 2850 & 3600 & 4700 & $1492,27+27,99 \mathrm{~N}-0,06 \mathrm{~N}^{2}$ & $0,996^{\star *}$ \\
\hline & RS & 1350 & 3000 & 3400 & 4000 & $1446,82+30,33 N-0,09 N^{2}$ & 0,970 ** \\
\hline & $\mathrm{RC}$ & 2000 & 3350 & 3850 & 4800 & $2068,18+24,82 \mathrm{~N}-0,06 \mathrm{~N}^{2}$ & $0,986^{* \star}$ \\
\hline $3^{\circ}$ & BS & 2850 & 3600 & 4000 & 4200 & $2862,27+16,58 \mathrm{~N}-0,05 \mathrm{~N}^{2}$ & $0,998^{* *}$ \\
\hline & $B C$ & 2550 & 3850 & 4150 & 4150 & $2615,45+25,75 \mathrm{~N}-0,09 \mathrm{~N}^{2}$ & $0,970^{* \star}$ \\
\hline & RS & 1550 & 2400 & 3050 & 3450 & $1541,82+20,28 N-0,05 N^{2}$ & $0,999^{* \star}$ \\
\hline & $\mathrm{RC}$ & 2350 & 2700 & 3250 & 3750 & $2390,00+7,11 \mathrm{~N}$ & $0,974^{\star *}$ \\
\hline $4^{\circ}$ & BS & 2000 & 2550 & 2450 & 4050 & $1900,00+9,86 \mathrm{~N}$ & $0,892^{* *}$ \\
\hline & $B C$ & 2250 & 2350 & 2800 & 3400 & $2170,00+6,06 \mathrm{~N}$ & $0,973^{\star *}$ \\
\hline & RS & 1300 & 2450 & 2800 & 2550 & $1339,55+24,80 N-0,09 N^{2}$ & $0,986^{\star \star}$ \\
\hline & $\mathrm{RC}$ & 1700 & 2300 & 2350 & 3550 & $1700,00+8,86 \mathrm{~N}$ & $0,952^{* *}$ \\
\hline
\end{tabular}

BS e RS: capins marandu e ruziziensis semeados simultaneamente ao milho, respectivamente; BC e RC: capins marandu e ruziziensis semeados por ocasião da adubação nitrogenada de cobertura do milho, respectivamente. ${ }^{\star \star} p<0,01$. 
análise de regressão (polinômios ortogonais), adotando-se a equação de maior coeficiente de determinação $\left(\mathrm{R}^{2}\right)(\mathrm{p}<0,05)$. As análises estatísticas foram realizadas utilizando o software estatístico SISVAR ${ }$ (Ferreira, 1999). Determinaram-se também as melhores equações de correlação do ICF com a PMS e o teor de PB, utilizando-se o software Excel.

\section{RESULTADOSEDISCUSSÃO}

A PMS foi influenciada pela interação tripla (consórcio $\times$ adubação nitrogenada $\times$ intervalo de crescimento) $(p<0,05)$, sendo que os consórcios BS, BC, RS e RC no $2^{\circ}$, $\mathrm{BS}, \mathrm{BC}$ e RS no $3^{\circ}$ e RS no $4^{\circ}$ intervalo de crescimento apresentaram regressão quadrática (tabela II). As demais interações apresentaram regressão linear em função das doses de N. Conforme Martha Júnior et al. (2007) a resposta das pastagens de gramíneas tropicais ao $\mathrm{N}$-fertilizante é expressiva até doses de $180 \mathrm{~kg} / \mathrm{ha}$ de N/ intervalo de crescimento, o que foi comprovado no presente estudo.

Com exceção do $3^{\circ}$ intervalo de cresimento, a PMS em função das doses de N nos consórcios dentro de cada época de corte foram semelhantes (tabela II), sendo que independente da época de consórcio com o milho, tal atributo foi menor no capimruziziensis. Os resultados do $1^{\circ}$ intervalo de cresimento demonstram que como as gramíneas não estavam plenamente estabelecidas no momento do corte de uniformização os consórcios foram prejudicados. Sem adubação, as PMS ficaram próximas aos $1200 \mathrm{~kg} / \mathrm{ha}$, o mínimo aceitável para corte ou consumo de bovinos em

Tabela III. Teores de proteína bruta (\% MS), dos capins marandu e ruziziensis após o consórcio com milho, intervalos de crescimento $\left(1^{\circ}, 2^{\circ}, 3^{\circ}\right.$ e $\left.4^{\circ}\right)$ e doses de $N$. (Crude protein (\% DM) contents of marandu and ruziziensis grasses after intercrop with corn, growth intervals $\left(1^{\circ}\right.$, $2^{\circ}, 3^{\circ}$ and $4^{\circ}$ ) and nitrogen fertilization).

\begin{tabular}{|c|c|c|c|c|c|c|c|}
\hline & & \multicolumn{4}{|c|}{ Dose de N (kg/ha) } & \multirow{2}{*}{ Equação estimada } & \multirow{2}{*}{$\mathrm{R}^{2}$} \\
\hline & & 0 & 50 & 100 & 200 & & \\
\hline \multirow[t]{4}{*}{$1^{\circ}$} & BS & 11,28 & 14,95 & 19,31 & 17,86 & $10,94+0,118905 \mathrm{~N}-0,000419 \mathrm{~N}^{2}$ & $0,964^{* *}$ \\
\hline & $\mathrm{BC}$ & 13,15 & 15,77 & 15,90 & 18,72 & $13,63+0,025730 \mathrm{~N}$ & $0,932^{* *}$ \\
\hline & RS & 10,54 & 15,48 & 20,52 & 19,50 & $10,21+0,146473 N-0,000498 N^{2}$ & $0,981^{* *}$ \\
\hline & $\mathrm{RC}$ & 11,55 & 19,64 & 21,86 & 21,52 & $11,90+0,165716 \mathrm{~N}-0,000591 \mathrm{~N}^{2}$ & $0,979 * *$ \\
\hline \multirow[t]{4}{*}{$2^{\circ}$} & BS & 11,73 & 12,49 & 14,42 & 16,26 & $11,67+0,023529 \mathrm{~N}$ & $0,976^{* *}$ \\
\hline & $\mathrm{BC}$ & 9,95 & 12,53 & 14,84 & 17,23 & $10,50+0,035791 \mathrm{~N}$ & $0,961^{\text {** }}$ \\
\hline & RS & 7,54 & 10,85 & 14,00 & 16,31 & $7,45+0,082780 \mathrm{~N}-0,000192 \mathrm{~N}^{2}$ & $0,997^{* *}$ \\
\hline & $\mathrm{RC}$ & 8,90 & 11,29 & 13,15 & 16,12 & $9,26+0,035446 \mathrm{~N}$ & 0,987 ** \\
\hline \multirow[t]{4}{*}{$3^{\circ}$} & BS & 10,77 & 12,51 & 12,27 & 14,82 & $10,96+0,018671 \mathrm{~N}$ & $0,912^{\star *}$ \\
\hline & $\mathrm{BC}$ & 8,97 & 12,92 & 13,86 & 15,35 & $9,21+0,072115 N-0,000209 N^{2}$ & 0,970 ** \\
\hline & RS & 8,84 & 11,87 & 11,37 & 15,52 & $9,22+0,030646 \mathrm{~N}$ & 0,900 ** \\
\hline & $\mathrm{RC}$ & 8,74 & 12,71 & 12,52 & 16,65 & $9,50+0,036063 N$ & $0,908^{* *}$ \\
\hline \multirow[t]{4}{*}{$4^{\circ}$} & BS & 12,42 & 14,17 & 15,58 & 18,15 & $12,61+0,028257 \mathrm{~N}$ & $0,995^{* *}$ \\
\hline & $B C$ & 10,43 & 14,99 & 15,74 & 17,27 & $10,74+0,080327 \mathrm{~N}-0,000241 \mathrm{~N}^{2}$ & $0,954^{\star *}$ \\
\hline & RS & 9,32 & 14,34 & 14,18 & 17,67 & $9,85+0,069641 \mathrm{~N}-0,000157 \mathrm{~N}^{2}$ & $0,904^{* *}$ \\
\hline & $\mathrm{RC}$ & 8,49 & 11,88 & 15,21 & 20,43 & $8,80+0,059406 \mathrm{~N}$ & $0,995^{\star \star}$ \\
\hline
\end{tabular}

BS e RS: capins marandu e ruziziensis semeados simultaneamente ao milho, respectivamente; BC e RC: capins marandu e ruziziensis semeados por ocasião da adubação nitrogenada de cobertura do milho, respectivamente. ${ }^{\star \star} p<0,01$. 
pastejo, segundo Mott (1980). No caso do capim-ruziziensis, tais resultados podem ter sido influenciados pelo corte de homogeneização, já que apresenta meristema apical mais alto e rebrota mais lenta do que o capim-marandu (Pires, 2006).

Com o aumento do fotoperíodo no início da primavera, ocorreu incremento da PMS e entre a $3^{\mathrm{a}}$ e $4^{\mathrm{a}}$ época de corte, ocorreu diminuição desta, possivelmente pelo corte das gemas apicais, o que pode ter dificultado o crescimento do capim no ciclo subsequente (tabela II). Assim, com o início da primavera recomenda-se aumentar a altura de corte dos capins marandu e ruziziensis. Tais resultados corroboraram com Barducci et al. (2009) que também verificaram respostas diferenciadas da PMS do capimmarandu consorciado simultaneamente ao milho ao longo dos cortes quando adubado com N. Enquanto que, no consórcio por ocasião da adubação nitrogenada de cobertura do milho, somente no início da primavera as gramíneas retomaram o perfilhamento expressando seu potencial produtivo, contudo não foi constatado no presente trabalho. No entanto, mesmo na ausência de adubação nitrogenada o sistema em estudo produziu quantidade satisfatória de forragem, com PMS média de $1733 \mathrm{~kg} / \mathrm{ha} \mathrm{no}$ inverno/primavera.

Também houve efeito das doses de $\mathrm{N}$ $(\mathrm{p}<0,05)$ no teor de $\mathrm{PB}$, sendo que o BS, RS e RC no $1^{\circ}$, o RS no $2^{\circ}$, o BC no $3^{\circ}$ e o BC e RS no $4^{\circ}$ intervalo de crescimento apresentaram regressão quadrática (tabela III). As demais interações do teor de PB apresentaram incremento linear com as doses de $\mathrm{N}$ e os maiores teores ocorreram no $1^{\circ}$ intervalo de crescimento e nessa época,

Tabela IV. Indice de clorofila foliar (ICF) dos capins marandu e ruziziensis após o consórcio com milho, intervalos de crescimento $\left(1^{\circ}, 2^{\circ}, 3^{\circ}\right.$ e $\left.4^{\circ}\right)$ e doses de $N$. (Leaf chlorophyll index of marandu and ruziziensis grasses after intercrop with corn, growth intervals $\left(1^{\circ}, 2^{\circ}, 3^{\circ}\right.$ e $\left.4^{\circ}\right)$ and nitrogen fertilization).

\begin{tabular}{|c|c|c|c|c|c|c|c|}
\hline & & & Dose $\mathrm{d}$ & $(\mathrm{kg} / \mathrm{ha}$ & & Equação estimada & $\mathrm{R}^{2}$ \\
\hline & & 0 & 50 & 100 & 200 & & \\
\hline $1^{0}$ & BS & 31,63 & 35,43 & 40,55 & 45,13 & $32,23+0,068014 \mathrm{~N}$ & $0,969 * \star$ \\
\hline & BC & 34,30 & 37,90 & 41,25 & 44,65 & $35,06+0,051029 \mathrm{~N}$ & $0,963^{\star \star}$ \\
\hline & RS & 26,20 & 40,50 & 43,83 & 47,28 & $27,01+0,268743 \mathrm{~N}-0,000844 \mathrm{~N}^{2}$ & $0,969 * *$ \\
\hline & $\mathrm{RC}$ & 34,08 & 39,30 & 45,18 & 50,40 & $35,12+0,081343 \mathrm{~N}$ & $0,962^{\star \star}$ \\
\hline $2^{\circ}$ & BS & 29,08 & 34,28 & 34,45 & 38,00 & $30,45+0,040057 \mathrm{~N}$ & $0,866^{\star \star}$ \\
\hline & BC & 30,65 & 35,98 & 41,95 & 41,18 & $30,25+0,162702 \mathrm{~N}-0,000537 \mathrm{~N}^{2}$ & $0,976 *$ \\
\hline & RS & 26,25 & 29,45 & 34,38 & 36,35 & $27,14+0,051100 \mathrm{~N}$ & $0,899 * *$ \\
\hline & $\mathrm{RC}$ & 25,05 & 32,38 & 35,68 & 37,23 & $25,24+0,156734 \mathrm{~N}-0,000486 \mathrm{~N}^{2}$ & $0,995^{*}$ \\
\hline $3^{\circ}$ & BS & 39,68 & 42,90 & 42,68 & 50,45 & $39,41+0,051600 \mathrm{~N}$ & $0,921^{\star *}$ \\
\hline & BC & 36,60 & 42,90 & 47,38 & 50,28 & $38,54+0,065686 \mathrm{~N}$ & $0,887^{\star *}$ \\
\hline & RS & 25,88 & 31,45 & 39,43 & 49,05 & $26,18+0,117371 \mathrm{~N}$ & $0,989 * *$ \\
\hline & $\mathrm{RC}$ & 29,20 & 30,60 & 39,90 & 46,20 & $31,63+0,070000 \mathrm{~N}$ & $0,953^{\star \star}$ \\
\hline $4^{\circ}$ & BS & 36,10 & 37,25 & 35,25 & 39,18 & 37,05 & ns \\
\hline & BC & 36,05 & 33,58 & 37,38 & 41,63 & $34,21+0,033671 \mathrm{~N}$ & $0,728^{*}$ \\
\hline & RS & 32,53 & 35,13 & 32,65 & 37,55 & 34,47 & ns \\
\hline & $\mathrm{RC}$ & 32,30 & 32,50 & 37,70 & 35,53 & 34,51 & ns \\
\hline
\end{tabular}

BS e RS: capins marandu e ruziziensis semeados simultaneamente ao milho, respectivamente; BC e RC: capins marandu e ruziziensis semeados por ocasião da adubação nitrogenada de cobertura do milho, respectivamente. ${ }^{*} p<0,05 ;{ }^{* *} p<0,01 ; n s$ : $p>0,05$. 
foram necessários menores doses de $\mathrm{N}$ para obtenção dos teores máximos de PB, sendo estes teores superiores aos verificados nos demais intervalos de crescimento. Cabe salientar o considerável teor de PB dos capins na ausência de adubação nitrogenada com média de $10,4 \%$ entre os consórcios. Os comportamentos quadráticos podem ter sido influenciados pelo intervalo de corte de 30 dias, sendo que nesses casos, a diminuição desse intervalo poderia alterar tal efeito.

Os teores máximos de $\mathrm{PB}$ não ultrapassaram a dose de $200 \mathrm{~kg} / \mathrm{ha}$ de $\mathrm{N}$ e aliado aos teores de PB na ausência de adubação, demonstra-se que o solo em estudo apresentou algum fornecimento de $\mathrm{N}$, possivelmente pelo início da mineralização da matéria orgânica e pela adubação residual do milho no consórcio (tabela III). $\mathrm{O} 1^{\circ}$ intervalo de crescimento apresentou ligeira superioridade de PB em relação às demais, principalmente pelas respostas quadráticas dos consórcios BS, RS e RC. Os teores de 7,45 a 23,94\% de PB foram satisfatórios, visto que foram superiores aos $7 \%$ considerados por Van Soest (1994) como mínimo para manutenção da população de microorganismos do rúmen de bovinos.

O ICF apresentou regressão quadrática para o RS no $1^{\circ}$ e o BC e RC no $2^{\circ}$ intervalo de crescimento (tabela IV). Os demais consórcios apresentaram efeito linear crescente em função das doses de $\mathrm{N}$ e apenas o BS, RS e RC no $4^{\circ}$ intervalo de crescimento não apresentaram significância (p>0,05). No $3^{\circ}$ intervalo de crescimento o ICF no capim-ruziziensis apenas aproximou dos verificados no capim-marandu com a aplicação de 200 kg/ha de N. Nos demais

Tabela V. Teores de nutrientes digestíveis totais (NDT) dos capins marandu e ruziziensis após o consórcio com milho, intervalos $\left(1^{\circ}, 2^{\circ}, 3^{\circ}\right.$ e $\left.4^{\circ}\right)$ de crescimento e doses de $N$. (Total digestible nutrients contents (TDN) of marandu and ruziziensis grasses after intercrop with corn, growth intervals $\left(1^{\circ}, 2^{\circ}, 3^{\circ}\right.$ e $\left.4^{\circ}\right)$ and nitrogen fertilization).

\begin{tabular}{|c|c|c|c|c|c|c|c|}
\hline & & \multicolumn{4}{|c|}{ Dose de N (kg/ha) } & \multirow[t]{2}{*}{ Equação estimada } & \multirow[t]{2}{*}{$\mathrm{R}^{2}$} \\
\hline & & 0 & 50 & 100 & 200 & & \\
\hline \multirow[t]{4}{*}{$1^{\circ}$} & BS & 58,71 & 58,99 & 60,18 & 59,24 & $59,28 \mathrm{~ns}$ & \\
\hline & $\mathrm{BC}$ & 58,17 & 59,60 & 58,48 & 60,88 & $58,26+0,011653 \mathrm{~N}$ & $0,656^{\star *}$ \\
\hline & RS & 59,29 & 60,71 & 62,16 & 61,06 & $59,18+0,045503 \mathrm{~N}-0,000180 \mathrm{~N} 2$ & $0,963^{\star *}$ \\
\hline & $\mathrm{RC}$ & 59,70 & 61,59 & 62,14 & 61,77 & $59,77+0,040305 \mathrm{~N}-0,000152 \mathrm{~N} 2$ & $0,983^{* *}$ \\
\hline \multirow[t]{4}{*}{$2^{\circ}$} & BS & 55,31 & 56,31 & 56,00 & 56,19 & $55,73+0,010261 \mathrm{~N}$ & $0,955^{\star *}$ \\
\hline & $\mathrm{BC}$ & 55,31 & 56,31 & 56,00 & 56,19 & 55,95 & ns \\
\hline & RS & 58,53 & 57,26 & 57,84 & 57,87 & 57,88 & ns \\
\hline & $\mathrm{RC}$ & 57,11 & 56,62 & 57,15 & 57,43 & 57,08 & ns \\
\hline \multirow[t]{4}{*}{$3^{\circ}$} & BS & 55,15 & 54,95 & 55,02 & 56,04 & 55,29 & ns \\
\hline & $\mathrm{BC}$ & 54,53 & 55,58 & 55,69 & 56,32 & $54,82+0,008096 \mathrm{~N}$ & $0,865^{*}$ \\
\hline & RS & 55,04 & 57,45 & 57,04 & 57,95 & $55,82+0,011981 \mathrm{~N}$ & $0,645^{\star *}$ \\
\hline & $\mathrm{RC}$ & 56,20 & 56,48 & 58,82 & 57,38 & $55,87+0,037612 \mathrm{~N}$ & $0,672^{* *}$ \\
\hline \multirow[t]{4}{*}{$4^{\circ}$} & BS & 54,20 & 56,94 & 57,46 & 57,58 & $54,35+0,052517 \mathrm{~N}-0,000183 \mathrm{~N} 2$ & $0,960^{* *}$ \\
\hline & $\mathrm{BC}$ & 54,33 & 55,77 & 55,91 & 56,79 & $54,73+0,011084 \mathrm{~N}$ & $0,863^{\star *}$ \\
\hline & RS & 55,95 & 58,26 & 57,67 & 59,08 & $56,59+0,013140 N$ & $0,716^{\star *}$ \\
\hline & $\mathrm{RC}$ & 54,67 & 56,17 & 56,94 & 58,33 & $54,99+0,017583 \mathrm{~N}$ & $0,963^{\star *}$ \\
\hline
\end{tabular}

BS e RS: capins marandu e ruziziensis semeados simultaneamente ao milho, respectivamente; BC e RC: capins marandu e ruziziensis semeados por ocasião da adubação nitrogenada de cobertura do milho, respectivamente. ${ }^{*} p<0,05 ;{ }^{*} p<0,01 ;$ ns: $p>0,05$. 
intervalos de crescimento, o comportamento do ICF dos capins marandu e ruziziensis foram bastante semelhantes. Benett et al. (2008) e Maranhão et al. (2009) avaliando o capim-marandu também verificaram efeito linear das doses de $\mathrm{N}$ no índice SPAD, que também é determinado por clorofilômetro.

Segundo Van Soest (1994), o estádio de maturidade da gramínea influencia mais o teor de FDN que a adubação nitrogenada. No entanto, apenas o BS no $1^{\circ}$, o BC, RS e $\mathrm{RC}$ no $2^{\circ}$ e o BS no $3^{\circ}$ intervalo de crescimento não apresentaram significância ( $p>0,05)$ dos teores de NDT e FDN em função das doses de $\mathrm{N}$ (tabelas V e VI). O RS e RC no $1^{\circ}$, o RC no $3^{\circ}$ e o BS no $4^{\circ}$ intervalo de crescimento apresentaram regressão quadrática para o teor de NDT e FDN. Da mesma forma que as demais interações, Barducci et al. (2009) avaliando o capim-marandu consorciado por ocasião da adubação nitrogenada do milho verificou efeito linear decrescente nos teores de FDN em função das doses de N, sendo que no geral também ocorreu aumento do teor de NDT.

Independente da época de consórcio com o milho, o capim-ruziziensis foi superior ao capim-marandu nos teores de NDT e inferior nos de FDN, visto que os teores de NDT foram calculados de forma inversa aos de FDN (tabelas V e VI). Os menores teores de FDN e os maiores de NDT foram verificados no $1^{\circ}$ intervalo de crescimento, independente do consórcio e da dose de $\mathrm{N}$. Borghi et al. (2006) verificaram $72 \%$ de FDN no capim-marandu consorciado nas entrelinhas do milho, enquanto que Benett et al. (2008) verificaram teores entre 69,64 e $64,66 \%$ no mesmo capim em monocultivo com as doses de 0 e $200 \mathrm{~kg} / \mathrm{ha}$ de $\mathrm{N}$,

Tabela VI. Teores de fibra em detergente neutro (FDN) dos capins marandu e ruziziensis após o consórcio com milho, intervalos de crescimento $\left(1^{\circ}, 2^{\circ}, 3^{\circ}\right.$ e $\left.4^{\circ}\right)$ e doses de $N$. (Neutral detergent fiber contents of marandu and ruziziensis grasses after intercrop with corn, growth intervals $\left(1^{\circ}, 2^{\circ}\right.$, $3^{\circ}$ and $4^{\circ}$ ) and nitrogen fertilization).

\begin{tabular}{|c|c|c|c|c|c|c|c|}
\hline & & \multicolumn{4}{|c|}{ Dose de N (kg/ha) } & \multirow[t]{2}{*}{ Equação estimada } & \multirow[t]{2}{*}{$\mathrm{R}^{2}$} \\
\hline & & 0 & 50 & 100 & 200 & & \\
\hline \multirow[t]{4}{*}{$1^{\circ}$} & BS & 60,13 & 59,47 & 56,60 & 58,86 & 58,77 & ns \\
\hline & $B C$ & 61,43 & 58,00 & 60,69 & 54,93 & $61,21-0,027979 \mathrm{~N}$ & $0,656^{\star \star}$ \\
\hline & RS & 58,73 & 55,34 & 51,85 & 54,49 & $59,00-0,109157 N+0,000431 N^{2}$ & $0,963^{* *}$ \\
\hline & $\mathrm{RC}$ & 57,76 & 53,23 & 51,90 & 52,79 & $57,59-0,096725 N+0,000365 N^{2}$ & $0,984^{*}$ \\
\hline \multirow[t]{4}{*}{$2^{\circ}$} & BS & 66,94 & 66,68 & 64,49 & 62,34 & $67,27-0,024616 \mathrm{~N}$ & $0,955^{\star *}$ \\
\hline & $\mathrm{BC}$ & 68,28 & 65,89 & 66,62 & 66,17 & 66,75 & ns \\
\hline & RS & 60,57 & 63,60 & 62,23 & 62,14 & 62,13 & ns \\
\hline & $\mathrm{RC}$ & 63,96 & 65,14 & 63,87 & 63,20 & 64,04 & ns \\
\hline \multirow[t]{4}{*}{$3^{\circ}$} & BS & 68,68 & 69,15 & 68,97 & 66,52 & 68,33 & ns \\
\hline & $\mathrm{BC}$ & 70,15 & 67,64 & 67,38 & 65,85 & $69,45-0,019357 \mathrm{~N}$ & $0,865^{*}$ \\
\hline & RS & 68,92 & 63,16 & 64,14 & 61,94 & $67,05-0,028723 \mathrm{~N}$ & $0,645^{\star *}$ \\
\hline & $\mathrm{RC}$ & 66,15 & 65,46 & 59,86 & 63,31 & $66,95-0,090178 N+0,000353 N^{2}$ & $0,671^{* *}$ \\
\hline \multirow[t]{4}{*}{$4^{\circ}$} & BS & 70,95 & 64,38 & 63,13 & 62,84 & $70,75-0,125779 N+0,000439 N^{2}$ & 0,960 ** \\
\hline & $\mathrm{BC}$ & 70,62 & 67,17 & 66,83 & 64,72 & $69,66-0,026566 \mathrm{~N}$ & $0,863^{\star *}$ \\
\hline & RS & 66,75 & 61,21 & 62,63 & 59,23 & $65,21-0,031506 \mathrm{~N}$ & $0,715^{\star *}$ \\
\hline & $\mathrm{RC}$ & 69,82 & 66,22 & 64,38 & 61,03 & $69,05-0,042144 \mathrm{~N}$ & $0,963^{\star \star}$ \\
\hline
\end{tabular}

BS e RS: capins marandu e ruziziensis semeados simultaneamente ao milho, respectivamente; BC e RC: capins marandu e ruziziensis semeados por ocasião da adubação nitrogenada de cobertura do milho, respectivamente. ${ }^{\star} p<0,05 ;{ }^{* *} p<0,01$; ns: $p>0,05$. 
respectivamente. Esses teores são superiores aos verificados no presente trabalho, principalmente quando se compara ao $1^{\circ}$ intervalo de crescimento. No entanto, os teores de FDN e NDT foram semelhantes aos relatados por Maranhão et al. (2009), provavelmente pela semelhança nos intervalos de corte e superiores aos 55\% de NDT relatados por Van Soest (1994) em forrageiras tropicais. Para reduzir o efeito da época do ano, pode-se aumentar o intervalo de corte no período seco, inclusive para elevar a PMS e diminuir este intervalo no período chuvoso, para obter forragem com menor teor de fibra e melhor valor nutritivo (aumento da PB e do NDT).

Os teores de FDA do BS, RS e RC no $2^{\circ}$, do $\mathrm{BC}$ no $3^{\circ}$ e $4^{\circ}$ e do RS no $4^{\circ}$ intervalo de crescimento não apresentaram significância ( $>>0,05)$ (tabela VII). Os teores de BS, RS e RC no $1^{\circ}$ e o BS e RC no $4^{\circ}$ intervalo de crescimento apresentaram regressão quadrática. Da mesma forma que Benett et al. (2008), inclusive com teores semelhantes e Cecato et al. (2004) com teores superiores, as demais interações ajustaram-se à regressões lineares em função das doses de N. Com excessão do BC no $2^{\circ}$ intervalo de crescimento, ocorreu um decréscimo do FDA em função do aumento dessas doses e no $1^{\circ}$ intervalo de crescimento ocorreram os menores teores de FDA. Os teores de FDA do presente trabalho também foram semelhantes aos relatados por Maranhão et al. (2009).

Com relação à lignina, o BS e RS em todos os intervalo de crescimento, o RC no $2^{\circ}$ e $4^{\circ}$ e o BC no $4^{\circ}$ intervalo de crescimento não apresentaram significância ( $>>0,05)$, enquanto que o RC no $1^{\circ}$ e $3^{\circ}$ e a RS no $3^{\circ}$ intervalo de crescimento apresentaram

Tabela VII. Teores de fibra em detergente ácido (FDA) dos capins marandu e ruziziensis após o consórcio com milho, intervalos de crescimento $\left(1^{\circ}, 2^{\circ}, 3^{\circ}\right.$ e $\left.4^{\circ}\right)$ e doses de $N$. (Acid detergent fiber contents of marandu and ruziziensis grasses after intercrop with corn, growth intervals $\left(1^{\circ}, 2^{\circ}\right.$, $3^{\circ}$ and $4^{\circ}$ ) and nitrogen fertilization).

\begin{tabular}{|c|c|c|c|c|c|c|c|}
\hline & & \multicolumn{4}{|c|}{ Dose de N (kg/ha) } & \multirow[t]{2}{*}{ Equação estimada } & \multirow[t]{2}{*}{$\mathrm{R}^{2}$} \\
\hline & & 0 & 50 & 100 & 200 & & \\
\hline \multirow[t]{4}{*}{$1^{\circ}$} & BS & 29,13 & 29,12 & 24,79 & 27,88 & $29,81-0,062607 \mathrm{~N}+0,000259 \mathrm{~N}^{2}$ & $0,558^{* *}$ \\
\hline & $\mathrm{BC}$ & 28,43 & 26,36 & 28,44 & 25,61 & $28,17-0,010940 \mathrm{~N}$ & $0,416^{*}$ \\
\hline & RS & 27,87 & 24,48 & 24,27 & 25,53 & $27,66-0,066156 N+0,000279 N^{2}$ & 0,931 ** \\
\hline & $\mathrm{RC}$ & 26,60 & 24,40 & 24,75 & 25,65 & $26,40-0,037754 N+0,000172 N^{2}$ & $0,827^{*}$ \\
\hline \multirow[t]{4}{*}{$2^{\circ}$} & BS & 32,87 & 34,89 & 33,60 & 32,61 & 33,49 & ns \\
\hline & $\mathrm{BC}$ & 32,96 & 34,60 & 34,74 & 35,18 & $33,53+0,009609 N$ & $0,714^{*}$ \\
\hline & RS & 30,16 & 30,66 & 31,41 & 31,36 & 30,90 & ns \\
\hline & $\mathrm{RC}$ & 30,88 & 34,19 & 32,06 & 32,95 & 32,52 & ns \\
\hline \multirow[t]{4}{*}{$3^{\circ}$} & BS & 32,95 & 32,60 & 34,46 & 30,59 & $32,56+0,031608 N-0,000204 N^{2}$ & $0,759^{* *}$ \\
\hline & $\mathrm{BC}$ & 33,89 & 33,58 & 34,46 & 32,27 & 33,55 & ns \\
\hline & RS & 33,71 & 32,51 & 32,24 & 28,26 & $34,03-0,026791 \mathrm{~N}$ & $0,936^{* *}$ \\
\hline & $\mathrm{RC}$ & 33,27 & 30,27 & 30,82 & 28,44 & $32,55-0,021114 \mathrm{~N}$ & $0,818^{*}$ \\
\hline \multirow[t]{4}{*}{$4^{\circ}$} & BS & 34,28 & 31,79 & 31,06 & 32,86 & $34,22-0,058723 N+0,000260 N^{2}$ & $0,994^{* *}$ \\
\hline & $\mathrm{BC}$ & 32,77 & 31,66 & 31,78 & 31,11 & 31,83 & ns \\
\hline & RS & 30,69 & 28,52 & 32,63 & 29,09 & 30,24 & ns \\
\hline & $\mathrm{RC}$ & 34,42 & 31,36 & 29,32 & 29,37 & $34,45-0,075915 N+0,000253 N^{2}$ & $0,999 * *$ \\
\hline
\end{tabular}

BS e RS: capins marandu e ruziziensis semeados simultaneamente ao milho, respectivamente; BC e RC: capins marandu e ruziziensis semeados por ocasião da adubação nitrogenada de cobertura do milho, respectivamente. ${ }^{*} p<0,05 ;{ }^{* *} p<0,01 ; n s: p>0,05$. 
regressão quadrática (tabela VIII). As demais interações apresentaram regressão linear em função das doses de $\mathrm{N}$ e com excessão do $\mathrm{BC}$ no $3^{\circ}$ intervalo de crescimento, ocorreu um decréscimo no teor de lignina em função do aumento das doses de N. No geral, os teores deste atributo foram bastante semelhantes entre os intervalos de crescimento, ficando entre 1 e $4 \%$.

Vale ressaltar que quanto maior o teor de FDA menor será a digestibilidade, enquanto que o FDN tem correlação negativa com o consumo das forrageiras, considerando teores de $40 \%$ de FDA e $60 \%$ de FDN, como limitantes da digestibilidade e do consumo, respectivamente (Van Soest, 1994). Assim, com exceção do $1^{\circ}$ intervalo de crescimento, no geral os teores de FDN foram superiores a 60\% (tabela VI), podendo-se afirmar que apesar da adubação nitrogenada, da irrigação, do intervalo de crescimento de 30 dias e da altura de corte de $30 \mathrm{~cm}$ (folhas principalmente), os capins marandu e ruziziensis apresentaram elevados teores de FDN. No entanto, os teores de FDA foram inferiores a 40\% (tabela VII), inferindo-se em uma forragem de menor consumo, mas de boa digestibilidade.

Em função da PMS obtida com o capimruziziensis (tabela II) e sua ligeira superioridade na composição bromatológica em relação ao capim-marandu (tabelas III, IV, V, VI, VII e VIII), sua utilização na ILP pode ser viabilizada por cortes ao invés de pastejo, visto que de acordo com Pires (2006), tal capim é sensível ao pisoteio excessivo dos animais.

A correlação positiva e elevada entre o ICF e o teor de PB é de grande importância na diagnose precoce de deficiências de $\mathrm{N}$, garantindo tomada de decisões em tempo hábil para possíveis adubações de cobertu-

Tabela VIII. Teores de lignina dos capins marandu e ruziziensis após o consórcio com milho, intervalos de crescimento $\left(1^{\circ}, 2^{\circ}, 3^{\circ}\right.$ e $\left.4^{\circ}\right)$ e doses de $N$. (Lignin contents of marandu and ruziziensis grasses after intercrop with corn, growth intervals $\left(1^{\circ}, 2^{\circ}, 3^{\circ}\right.$ and $\left.4^{\circ}\right)$ and nitrogen fertilization).

\begin{tabular}{|c|c|c|c|c|c|c|c|}
\hline & & \multicolumn{4}{|c|}{ Dose de N (kg/ha) } & \multirow[t]{2}{*}{ Equação estimada } & \multirow[t]{2}{*}{$\mathrm{R}^{2}$} \\
\hline & & 0 & 50 & 100 & 200 & & \\
\hline \multirow[t]{4}{*}{$1^{\circ}$} & BS & 2,27 & 2,42 & 2,73 & 2,16 & 2,40 & ns \\
\hline & $B C$ & 2,19 & 1,97 & 1,89 & 1,34 & $2,21-0,004171 \mathrm{~N}$ & $0,969 * \star$ \\
\hline & RS & 2,05 & 1,49 & 2,25 & 1,62 & 1,85 & ns \\
\hline & $\mathrm{RC}$ & 2,80 & 1,68 & 1,74 & 1,99 & $2,71-0,019633 \mathrm{~N}+0,000081 \mathrm{~N}^{2}$ & $0,870^{\star \star}$ \\
\hline \multirow[t]{4}{*}{$2^{\circ}$} & BS & 2,47 & 2,40 & 2,13 & 2,41 & 2,35 & ns \\
\hline & $\mathrm{BC}$ & 1,93 & 2,32 & 3,04 & 3,37 & $2,02-0,007393 \mathrm{~N}$ & $0,918^{\star \star}$ \\
\hline & RS & 2,13 & 2,79 & 1,97 & 2,19 & 2,27 & ns \\
\hline & $\mathrm{RC}$ & 2,11 & 3,04 & 1,80 & 2,62 & 2,39 & ns \\
\hline \multirow[t]{4}{*}{$3^{\circ}$} & BS & 1,45 & 1,29 & 1,68 & 1,65 & 1,52 & ns \\
\hline & BC & 1,83 & 1,37 & 2,08 & 2,56 & $1,55+0,004689 \mathrm{~N}$ & $0,648^{\star *}$ \\
\hline & RS & 1,61 & 1,73 & 2,28 & 1,81 & $1,53+0,010363 \mathrm{~N}-0,000044 \mathrm{~N}^{2}$ & $0,715^{*}$ \\
\hline & $\mathrm{RC}$ & 2,07 & 1,35 & 1,46 & 1,62 & $2,00-0,011783 \mathrm{~N}+0,000050 \mathrm{~N}^{2}$ & $0,803^{*}$ \\
\hline \multirow[t]{4}{*}{$4^{\circ}$} & BS & 2,30 & 2,15 & 1,40 & 2,16 & 2,00 & ns \\
\hline & $\mathrm{BC}$ & 2,27 & 1,95 & 2,02 & 2,00 & 2,06 & ns \\
\hline & RS & 2,22 & 2,51 & 2,21 & 2,87 & 2,46 & ns \\
\hline & $\mathrm{RC}$ & 2,28 & 2,38 & 2,28 & 2,56 & 2,38 & ns \\
\hline
\end{tabular}

BS e RS: capins marandu e ruziziensis semeados simultaneamente ao milho, respectivamente; BC e RC: capins marandu e ruziziensis semeados por ocasião da adubação nitrogenada de cobertura do milho, respectivamente. ${ }^{*} p<0,05$; ${ }^{* *} p<0,01$; ns: $p>0,05$. 
Tabela IX. Matriz de correlação linear entre a produtividade de matéria seca em 30 dias (PMS), o índice de clorofila foliar (ICF) e a composição bromatológica dos capins marandu $e$ ruziziensis. (Linear correlation matrix between the dry matter yield in 30 days, leaf chlorophyll index and chemical composition of marandu and ruziziensis grasses).

\begin{tabular}{|c|c|c|c|c|c|c|}
\hline \multirow[b]{2}{*}{ Atributo } & \multicolumn{6}{|c|}{ Coeficiente de correlação } \\
\hline & PMS & ICF & NDT & PB & FDN & FDA \\
\hline \multicolumn{7}{|c|}{ Brachiaria brizantha cv. marandu } \\
\hline ICF & $0,4747^{\star \star}$ & - & - & - & - & - \\
\hline NDT & $-0,4047$ ** & $0,0723 n s$ & - & - & - & - \\
\hline PB & $0,1006 n s$ & $0,3570^{\star *}$ & $0,6398 * *$ & - & - & - \\
\hline FDN & $0,4047^{\star *}$ & $-0,0723 n s$ & $-1,0000^{* *}$ & $-0,6398^{* *}$ & - & - \\
\hline FDA & $0,6054^{* *}$ & $-0,0669 n s$ & $-0,8049^{* *}$ & $-0,4739 * *$ & $0,8049^{* *}$ & \\
\hline Lignina & $0,0999 n s$ & $-0,0309 n s$ & $0,0079 \mathrm{~ns}$ & $0,1825^{\star}$ & $-0,0079 n s$ & $0,1909^{*}$ \\
\hline \multicolumn{7}{|c|}{ Brachiaria ruziziensis } \\
\hline ICF & $0,1381^{*}$ & - & - & - & - & - \\
\hline NDT & $-0,3053^{\star *}$ & $0,5007^{\star *}$ & - & - & - & - \\
\hline PB & $0,1127 \mathrm{~ns}$ & $0,7011^{\star *}$ & $0,7141^{* *}$ & - & - & - \\
\hline FDN & $0,3053^{* *}$ & $-0,5007^{\star *}$ & $-1,0000 * *$ & $-0,7141^{* *}$ & - & - \\
\hline FDA & $0,4312^{\star *}$ & $-0,4997^{\star *}$ & $-0,8454^{\star \star}$ & $-0,6458^{\star *}$ & $0,8454^{\star *}$ & - \\
\hline Lignina & $0,1323 \mathrm{~ns}$ & $-0,2350$ ** & $-0,1982^{*}$ & $-0,0754 \mathrm{~ns}$ & $0,1982^{*}$ & $0,2734^{* *}$ \\
\hline
\end{tabular}

PMS: produtividade de matéria seca em 30 dias; ICF: índice de clorofila foliar; NDT: nutrientes digestíveis totais; PB: proteína bruta; FDN: fibra em detergente neutro FDA: fibra em detergente ácido.

${ }^{*} p<0,01 ;{ }^{*} p<0,05 ;$ ns: significativo.

ra desse nutriente. Assim, o índice de clorofila pode ser usado como indicador da PMS e das necessidades de adubação nitrogenada. Em função do elevado número de observações por capim $(n=128)$, os coeficientes de correlação do ICF com a PMS e a PB se apresentaram entre bem fraco e forte $(0,13$ a 0,70$)$, no entanto significativos para o par de atributo ICF $\times$ PMS $(\mathrm{p}<0,05)$ no capim-ruziziensis e $(\mathrm{p}<0,01)$ nos demais pares de atributos (tabela I). As equações (tabela IX) que apresentaram maior coeficiente de determinação $\left(\mathrm{R}^{2}\right)$ em função do ICF foram logarítima para a PMS e potencial para a PB do capim-marandu e potencial para ambos os atributos do capim-ruziziensis: PMS capim-marandu=-9.836,43 + 3.445,77 ln ICF; PMS capim-ruziziensis $=627,862$ ICF0,36; PB capim-marandu= 2,319 ICF0,492; PB capim-ruziziensis=0,295 ICF1,07.

\section{CONCLUSÕES}

Em sistema de integração lavourapecuária irrigado sob condições de cerrado é tecnicamente viável o estabelecimento dos capins marandu e ruziziensis pelo consórcio com o milho no momento da semeadura ou por ocasião da adubação nitrogenada de cobertura. Após a colheita do milho, a adubação nitrogenada, eleva a produtividade de matéria seca e melhora a composição bromatológica dos capins, com aumento do índice de clorofila foliar e dos teores de proteína bruta e nutrientes digestíveis totais, além de reduzir os teores de fibra em detergente neutro e ácido no inverno/primavera. As melhores equações de correlação em função do ICF foram logarítima para a PMS e potencial para a PB do capim-marandu e potencial para ambos os atributos do capim-ruziziensis. 


\section{PARIZ, ANDREOTTI, BERGAMASCHINE, BUZETTI, COSTAE CAVALLINI}

\section{BIBLIOGRAFIA}

Abreu, J.B.R. e F.A. Monteiro. 1999. Produção e nutrição do capim-marandu em função de adubação nitrogenada e estádios de crescimento. B. Indústr. Anim., 56: 137-146.

Barducci, R.S., Costa, C., Crusciol, C.A.C., Borghi, É., Putarov, T.C. e L.M.N. Sarti. 2009. Produção de Brachiaria e Panicum maximum com milho e adubação nitrogenada. Arch. Zootec., 58: 211-222.

Benett, C.C.S., Buzetti, S., Silva, K.S., Bergamaschine, A.F. e Fabricio, J.A. 2008. Produtividade e composição bromatológica do capim-marandu a fontes e doses de nitrogênio. Cienc. Agrotec., 32: 1629-1636.

Borghi, É., Crusciol, C.A.C., Costa, C. e Mateus, G.P. 2006. Produtividade e qualidade das forragens de milho e de Brachiaria brizantha em sistema de cultivo consorciado. Rev. Bras. Milho e Sorgo, 5: 369-381.

Cappelle, E.R., Valadares Filho, S. de C., Silva, J.F.C. da e Cecon, P.R. 2001. Estimativas do valor energético a partir de características químicas e bromatológicas dos alimentos. Rev. Bras. Zootecn., 30: 1837-1856.

Cecato, U., Pereira, L.A.F., Jobim, C.C., Martins, E.N., Branco, A.F., Galbeiro, S. e Machado, A.O. 2004. Influência das adubações nitrogenada e fosfatada sobre a composição químicobromatológica do capim marandu (Brachiaria brizantha (Hochst) Stapf cv. marandu). Acta Sci. Anim. Sci., 26: 409-416.

EMBRAPA. 2006. Sistema brasileiro de classificação de solos. $2^{a}$ ed. Embrapa/CNPS. Rio de Janeiro. 306 pp.

Ferreira, D.F. 1999. SISVAR: Sistema de análise de variância. UFLA/DEX. Lavras.

Kluthcouski, J., Cobucci, T., Aidar, H., Yokoyama, L.P., Oliveira, I.P. de, Costa, J.L. da S., Silva, J.G. da, Vilela, L., Bacellos, A. de O. e Magnabosco, C. de U. 2000. Sistema Santa Fé -Tecnologia Embrapa: integração lavoura-pecuária pelo consórcio de culturas anuais com forrageiras, em áreas de lavoura, nos sistemas direto e con- vencional. Embrapa Arroz e Feijão. Santo Antonio de Goiás, GO. Circular Técnica 38. 28 pp.

Landers, J.N. 2007. Tropical crop-livestock systems in conservation agriculture: the Brazilian experience. In: Integrated crop management. $1^{\mathrm{a}}$ ed. Food and Agriculture Organization of the United Nations (FAO). Rome. Vol. 5. 92 pp.

Maranhão, C.M. de A., Silva, C.C.F. da , Bonomo, P. e Pires, A.J.V. 2009. Produção e composição bromatológica de duas cultivares de braquiária adubadas com nitrogênio e sua relação com o índice SPAD. Acta Sci. Anim. Sci., 31: 117122.

Martha Júnior, G.B., Vilela, L. e Sousa, D.M.G. 2007. Adubação nitrogenada. In: Martha Júnior, G.B., Vilela, L. e Sousa, D.M.G. (Eds.). Uso eficiente de corretivos e fertilizantes em pastagens. $1^{\mathrm{a}} \mathrm{ed}$. Embrapa Cerrados. Planaltina. Cap. 6: 117-144.

Mott, G.O. 1980. Measuring forage quantity and quality in grazing trials. Southern pasture and forage crop improvement conference. Resumo de palestras... AESA/ARS. Nashville. pp. 3-9.

Pires, W. 2006. Manual de pastagem: formação, manejo e recentiuperação. Aprenda Fácil. Viçosa. 302 pp.

Rocha, R.N.C., Galvão, J.C.C., Teixeira, P.C., Miranda, G.V., Agnes, E.L., Pereira, P.R.G. e Leite, U.T. 2005. Relação do índice SPAD, determinado pelo clorofilômetro, com teor de nitrogênio na folha e rendimento de grãos em três genótipos de milho. Rev. Bras. Milho e Sorgo, 4: 161-171.

Silva, D.J. e Queiroz, A.C. 2002. Análise de alimentos: métodos químicos e biológicos. $3^{\mathrm{a}} \mathrm{ed}$. UFV. Viçosa. 235 pp.

Tracy, B.F. e Zhang, Y. 2008. Soil compaction, corn yield response, and soil nutrient pool dynamics within an integrated crop-livestock system in Illinois. Crop Sci., 48: 1211-1218.

Van Soest, P.J. 1994. Nutritional ecology of the ruminant. $2^{\text {nd }}$ ed. Cornell University. New York. $476 \mathrm{pp}$. 